\title{
Controle de Cosmopolites sordidus (Coleoptera:Curculionidae) com os fungos entomopatogênicos Beauveria bassiana e Metarhizium anisopliae em banana
}

\section{Control of Cosmopolites sordidus (Coleoptera:Curculionidae) with entomopathogenic fungi Beauveria bassiana and Metarhizium anisopliae in banana cultivation}

\author{
Francisco José Carvalho Moreira ${ }^{1 *}$, Beatriz de Abreu Araújo ${ }^{2}$, Vanádia Farias da Silva ${ }^{3}$, Neyreane de Sousa Luna ${ }^{4}$ Ozeládia \\ Parente Araújo ${ }^{4}$, Roberto Davi dos Santos Braga ${ }^{3}$
}

\begin{abstract}
Resumo: O uso contínuo de agrotóxicos promove uma redução rápida e eficaz das pragas, contudo, esta prática acarreta nas pragas a possibilidade de desenvolver resistência, sujeitando o agricultor a mudar constantemente de produto, aumentar a dose ou até mesmo misturar ou usar produtos ainda mais tóxicos. Sendo Cosmopolites sordidus um coleóptero de hábitos noturnos que prejudica a bananeira, pois suas larvas abrem galerias no seu rizoma e na parte inferior do pseudocaule, acarretando em declínio, tombamento e morte da planta. Em vista disso e da própria conscientização da população para este problema maior tem sido a participação da agricultura orgânica na oferta de alimentos. Neste contexto, este trabalho teve por objetivo avaliar o efeito de dois fungos entomopatogênicos no controle de $C$. sordidus no cultivo de bananeira. O ensaio foi realizado no Perímetro Irrigado do Baixo Acaraú, em Marco, Ceará. O delineamento estatístico utilizado foi o inteiramente casualizado, em esquema fatorial 2 x 5, sendo dois fungos (Beauveria bassiana e Metharizium anisopliae) em cinco concentrações (0, 5, 10, 15 e $20 \mathrm{~g} \mathrm{~L}^{-1}$ ), com 5 repetições cada. Avaliou-se o número de insetos por iscas, em cada avaliação e o número total de insetos capturados. Verificou-se que o fungo B. bassiana foi mais efetivo no controle de $C$. sordidus. Observou-se ainda que as maiores concentrações, de 10,15 e $20 \mathrm{~g} \mathrm{~L}^{-1}$, mostraram-se mais eficientes. Conclui-se que o controle biológico com $B$. bassiana pode ser utilizado, pois mostrou-se adaptado as condições climáticas na região de estudo.
\end{abstract}

Palavras-chave: Controle biológico; Sustentabilidade; Broca do rizoma; Musa sp.; FHIA 18.

\begin{abstract}
The continuous use of pesticides promotes rapid and effective reduction of pests, however, this practice entails the pests the possibility of developing resistance by subjecting the farmer to change product constantly increase the dose or even mix or use more toxic products. Being Cosmopolites sordidus one beetle nocturnal that affect the banana tree because their larvae open galleries in its rhizome and lower pseudostem, resulting in decline, overturning and death of the plant. In view of this and the population's awareness of this problem, the greater has been the participation of organic agriculture in food supply. In this context, this study aimed to evaluate the effect of two entomopathogenic fungi in control of $C$. sordidus in banana cultivation. The trial was held in lot E-104, the Irrigated Perimeter of Baixo Acaraú, in Marco, Ceará state. The statistical design was completely randomized, in factorial 2 x 5, two fungi (Beauveria bassiana and Metharizium anisopliae) in five concentrations $\left(0,5,10,15\right.$ and $\left.20 \mathrm{~g} \mathrm{~L}^{-1}\right), 5$ repetitions each. We evaluated the number of insects for bait in each evaluation and the total number of captured insects. It was found that the fungus $B$. bassiana was more effective in controlling $C$. sordidus. It was also observed that the higher concentrations of 10,15 and $20 \mathrm{~g} \mathrm{~L}^{-1}$ were more effective. We conclude that the biological control with $B$. bassiana can be used, as is shown adapted to climatic conditions in the study area.
\end{abstract}

Key words: Biological control; Sustainability; Banana weevil borer; Musa sp.; FHIA 18.

\footnotetext{
*Autor para correspondência

Recebido para publicação em 03/11/2016; aprovado em 23/06/2017

${ }^{1}$ Eng. Agrônomo, MSc., Doutorando em Biotecnologia (RENORBIO/UFRN), prof. do Eixo de Recursos Naturais (Laboratório de Fitossanidade e Sementes) do Instituto Federal de Educação, Ciência e Tecnologia do Ceará - IFCE - Campus Sobral, Av. Dr. Guarani, Nº 317, Bairro Derby Clube - CEP: 62.042-030 Sobral - CE; (88) 3112-8100, E-mail: franzecm@gmail.com

${ }^{2}$ Tecnóloga em Irrigação e Drenagem, IFCE - Campus Sobral, Sobral, CE, Mestrando em Engenharia Agrícola, PPGEA/UFC, E-mail: bia10_pcj@hotmail.com

${ }^{3}$ Técnicos em Fruticultura, IFCE - Campus Sobral, Sobral, CE, (autônomos), E-mail: vanadia_farias@hotmail.com, davidsp_520@hotmail.com

${ }^{4}$ Tecnólogas em Irrigação e Drenagem, IFCE - Campus Sobral, Sobral, CE, E-mail: neyreaneluna21@gmail.com; ozelandia@ @otmail.com
} 


\section{INTRODUÇÃO}

A banana é um dos frutos mais produzidos e consumidos em todo o mundo, com uma produção mundial de aproximadamente 100,0 milhões de toneladas em 2010. Seu cultivo e produção estão entre os principais segmentos agrícolas da nossa economia, fazendo parte de um agronegócio eficiente, com elevada importância econômica e social, gerando empregos diretos e indiretos, além de proporcionar aumento nas divisas do país, em vista das suas exportações. É uma das culturas perenes que permite retorno mais rápido do capital investido. Isso porque a partir do primeiro ano de cultivo já apresenta produção econômica, tornando-se uma atividade atrativa tanto para grandes, médios e pequenos produtores. Se destacando bastante como uma atividade muito propícia, em função da grande demanda de mão-de-obra, principalmente familiar.

A produção brasileira de banana coloca o país como o quinto maior produtor mundial, com a produção, em 2012, de 6,833 milhões de toneladas e área plantada de 520.766 hectares, apresentando como principais produtores nacionais São Paulo, Bahia, Santa Catarina, Minas Gerais e Pará respectivamente (IBGE, 2012).

A bananeira (Musa sp.) sofre o ataque de inúmeras pragas, algumas das quais se destacam pela sua presença constante e de ampla distribuição geográfica. Em outras situações a incidência de pragas é mais regionalizada e, nem por isso, menos prejudicial. Assim, conhecer os problemas fitossanitários que afetam o cultivo, saber identificá-los e ter informações sobre as medidas adequadas de controle são subsídios fundamentais para a tomada de decisão do produtor. Ressalta-se que na agricultura atual não basta apenas à constatação da praga na área cultivada sem levar em consideração a população da praga como um todo, seu nível de controle e o dano econômico que a mesma acarreta. São esses fatores que combinados determinarão à necessidade de medidas de controle (COSTA et al., 2010; SILVA et al., 2011).

O moleque da bananeira (Cosmopolites sordidus Coleoptera: Curculionidae), também conhecido como broca da bananeira e broca do rizoma é, atualmente, a principal praga da cultura da bananeira. Esta praga se localiza no rizoma das plantas, onde se alojam, formando galerias, em muitos casos também afetando o pseudocaule. Em vista disso, as plantas diminuem a capacidade de absorção de água e nutrientes, com isso as mesmas ficam mais susceptíveis a entrada de doenças e também se tornam mais vulneráveis aos ventos, principalmente quando as plantas estão em fase reprodutiva, devido ao peso dos cachos (MICHEREFF FILHO et al., 2010; BATISTA FILHO et al., 2005).

A ocorrência dessa praga no Brasil foi constatada em 1915, no Rio de Janeiro; a partir dessa data foi encontrada em todos os estados brasileiros que cultivam banana, atacando com maior ou menor intensidade todas as cultivares. Os prejuízos são provocados pela debilidade e até morte de plantas, principalmente as mais jovens, e pela redução da colheita, causada por uma diminuição do peso dos cachos ou por tombamento das bananeiras. Em algumas regiões, as altas populações de brocas encontradas nos bananais podem reduzir a produção em até $80 \%$ (BATISTA FILHO et al., 2016).

O inseto pertence à família Curculionidae, caracterizada pela presença de um prolongamento anterior na forma de tromba ou bico longo e recurvado, em cuja extremidade estão inseridas as peças bucais mastigadoras. Sua coloração é preta, mede por volta de $11 \mathrm{~mm}$ de comprimento e 5,0 $\mathrm{mm}$ de largura. Os adultos têm hábito noturno e são encontrados em ambientes úmidos e sombreados, junto às touceiras, entre as bainhas foliares e nos restos culturais. A longevidade do adulto varia de alguns meses a dois anos (BATISTA FILHO et al., 2016; CAVALCANTI et al., 2002).

As fêmeas de $C$. sordidus depositam seus ovos no interior do rizoma, em pequenas cavidades feitas com o rostro, a 1,0 ou 2,0 $\mathrm{mm}$ de profundidade. A oviposição ocorre em toda a superfície do rizoma, com a maior quantidade dos ovos distribuída na sua metade superior. Contudo, tem-se observado que um número considerável de bananeiras apresentam seus rizomas atacados apenas na parte inferior. $\mathrm{O}$ período de incubação varia de acordo com o ambiente. As galerias no rizoma também causam danos indiretos, favorecendo a penetração de patógenos nas áreas atacadas, causando podridões e morte da planta (CAVALCANTI et al., 2002; MICHEREFF FILHO et al., 2010; COSTA et al., 2010; ROSSETTI, 2013; BATISTA FILHO et al., 2016).

De acordo com Borges et al., (2002) a maioria das cultivares de bananeira, em uso atualmente são muito suscetíveis ao ataque da broca do rizoma (moleque da bananeira), que são cultivadas principalmente nas regiões Norte e Nordeste, onde muitas vezes os solos são arenosos, rasos e pobres em nutrientes, e, atrelado a isso, constata-se a falta de estudos e de informações sobre essas cultivares, o que leva à prática de manejo sem técnicas adequadas Os principais problemas enfrentados pelos produtores, além da comercialização, são a alta incidência de $C$. sordidus, dentre outros problemas fitossanitários, o manejo da planta e as técnicas de adubação

Segundo Almeida et al., (2009) a principal forma de controle desta praga, de forma rápida e eficaz, é o controle químico, com a utilização de inseticidas sistêmicos que demandam cuidados especiais durante o manuseio e a aplicação. Além disso, o fato do princípio ativo desses inseticidas se translocar via seiva até os frutos, que são comercializados quase na sua totalidade "in natura", pode trazer problemas de resíduo, já que os períodos de carências destes produtos são elevados.

É preocupante a crescente utilização irracional de defensivos agrícolas (agrotóxicos). Este fato deve-se a elevada demanda por alimentos, fibras e biocombustíveis, em que há a necessidade de eliminação das pragas e doenças. Para se conseguir este imperativo aumento da produção aliada à preservação ambiental é interessante que se busque alternativas eficazes e viáveis para a substituição de tais produtos, que impõem ao homem e ao meio ambiente consequências calamitosas. Portanto, a nossa meta é responder a esse grande desafio de aumento de produtividade, que depende de novas tecnologias que por sua vez dependem da aplicação destes insumos. Em vista disso, salienta-se que os inseticidas usualmente empregados no controle da broca do rizoma vêm sofrendo sérias objeções, além de serem utilizados com restrição na Produção Integrada (PI), e inadmissíveis na produção orgânica de alimentos (SILVA et al., 2011; LINS et al., 2013).

O uso frequente dos defensivos químicos de síntese (agrotóxicos) promovem redução não só das pragas, mas também dos organismos benéficos (abelhas, vespas polinizadores), fazendo com que cada vez mais o agricultor 
seja dependente de tais produtos. Em vista disso, acarreta em a praga adquirir resistência, ficando muito difícil de ser controlada, obrigando, portanto, o agricultor aumentar a dosagem, mudar de produto, ou até mesmo misturá-los ou usar produtos ainda mais tóxicos ou não registrados para aquelas culturas (DALZOTO; UHR, 2009; BATISTA FILHO et al., 2016). Nesse sentido, faz-se necessário um acompanhamento constante, e eficaz destas práticas, pois os agrotóxicos não só são danosos apenas às pragas, mas também para o homem, os animais domésticos e silvestres e, para a natureza como um todo, podendo deixar resíduos tóxicos nos alimentos ou na água.

Muitos autores têm estudado alguns produtos sucedâneos como alternativa ao controle de pragas, doenças e plantas daninhas, como extratos vegetais, urina de vaca, soro de leite, bactérias, vírus e fungos entomopatogênicos, com o intuito de se alcançar este objetivo. Dentre os fungos entomopatogêncos mais estudados encontram-se Beauveria bassiana e Metarhizium anisopliae, dos quais já se tem extensivos trabalhos comprobatórios de sua eficácia, sendo produzido em larga escala no Brasil, atacando mais de trezentas espécies de insetos (CAVALCANTI et al., 2002; DALZOTO; UHR, 2009; MOURA et al., 2015; BATISTA FILHO et al., 2016).

Dentre os agentes biológicos que naturalmente controlam o tamanho das populações de insetos e que poderiam ser empregados em programas de controle microbiológico, estão os fungos entomopatogênicos. Os fungos entomopatogênicos penetram no hospedeiro via tegumento, o que os coloca em vantagem quando comparados com outros grupos de patógenos que só entram no inseto por via oral. Evidências obtidas por microscopia eletrônica e histoquímica sugerem que a etapa de penetração ocorre por uma combinação de degradação enzimática e pressão mecânica (LEITE et al., 2002). As enzimas proteolíticas ou proteases, além de estarem envolvidas nos processos de formação e germinação dos conídios, têm funções nutricionais importantes, sendo capazes de hidrolisar as cadeias polipeptídicas em cadeias menores, que são absorvidas pelas células (TIAGO; SILVA, 2007).

A produção de proteases tem sido estudada com várias finalidades, como a de correlacioná-las com os processos de especificidade, patogenicidade e virulência. Assim, diversos estudos associados à produção de proteases por $M$. anisopliae demonstram uma grande variabilidade genética entre os isolados, quando cultivados em meios de cultura contendo diferentes fontes de carbono e nitrogênio, não existindo relatos a respeito de atividade proteolítica frente às cutículas das cigarrinhas $M$. fimbriolata e D. flavopicta (COSTA et al., 2010; TIAGO; SILVA, 2010).

O fungo entomopatogênico Metarhizium anisopliae tem sido utilizado no controle biológico de cigarrinhas que atacam pastagens e cana-de-açúcar, sendo este um dos programas mais antigos, no qual foram realizados estudos de coleta e seleção de isolados com diferentes graus de virulência, de especificidade para cada praga visada e de adaptação a condições ambientais diversas. O fungo Beauveria bassiana (Balsamo) Vuillemin 1912 pertence à classe Hyphomycetes, família Moniliaceae, e é comumente encontrado no solo. É uma das espécies mais estudadas no controle de artrópodes, provavelmente em função da ampla distribuição geográfica e da variedade de seus hospedeiros, este fungo pode causar doenças em mais de 200 espécies de insetos (CAVALCANTI et al., 2002; DALZOTO; UHR, 2009; MOURA et al., 2015).

Em vista do exposto, este trabalho teve por objetivo avaliar o efeito de cinco concentrações dos fungos entomopatogênicos (B. bassaiana e $M$. anisopliae) no controle biológico de moleque da bananeira (C. sordidus).

\section{MATERIAL E MÉTODOS}

O trabalho foi desenvolvido em área de produção comercial, no Perímetro de Irrigação Baixo Acaraú, no município de Marco no Estado do Ceará, no período de abril a maio de 2012, perfazendo 35 dias.

O referido Perímetro apresenta como coordenadas geográficas latitude sul $03^{\circ} 01^{\prime}$ a $03^{\circ} 22^{\prime}$; longitude oeste $40^{\circ} 01^{\prime}$ a $40^{\circ} 09^{\prime}$. O clima segundo a classificação de Köppen é do tipo $\mathrm{AW}$ ', tropical chuvoso com chuvas máximas no outono (março a abril). A temperatura média anual é de $28^{\circ} \mathrm{C}$, umidade relativa do ar de $70 \%$, precipitação pluviométrica média de $1.024 \mathrm{~mm}$ e altitude variando de 36 a $56 \mathrm{~m}$. Os tipos predominantes de solos são das classes dos Argilossolos, Latossolos e Neossolos são solos profundos, bem drenados, de textura leve e muito permeável (EMBRAPA, 1999).

Para este estudo utilizou-se isolados dos fungos Metarhizium anisopliae e Beauveria bassiana produzidos pela Itaforte Industrial de Bioprodutos Agro-Florestais Ltda, sob os nomes comerciais: Metarril $^{\circledR}$ e Boveril $^{\circledR}$, respectivamente.

A área onde foi realizado este ensaio constou de uma área de produção comercial, cultivada com banana (Musa paradisiaca L.), CV FHIA 18, no espaçamento de 2,5 m x 2,0 $\mathrm{m}$, com dois anos e meio de implantada e em plena produção. A escolha desta variedade deu-se em razão de ser uma das mais afetadas pela broca do rizoma.

A primeira parte do ensaio constou do monitoramento do nível populacional do inseto e da escolha do melhor tipo de isca para captura e tratamento dos mesmos. Para tanto, procedeu-se da confecção 10 iscas tipo queijo (Figura 1A) e 10 tipo telha (Figura 1B) as quais foram espalhadas aleatoriamente na área de cultivo, 0,8 ha, sempre junto às touceiras. A avaliação foi realizada 48 horas após a implantação das iscas.

Figura 1. Mostra os dois tipos de iscas para captura de broca da bananeira ( $C$. sordidus), queijo (A) e telha (B), respectivamente, utilizadas para o monitoramento da população de insetos.
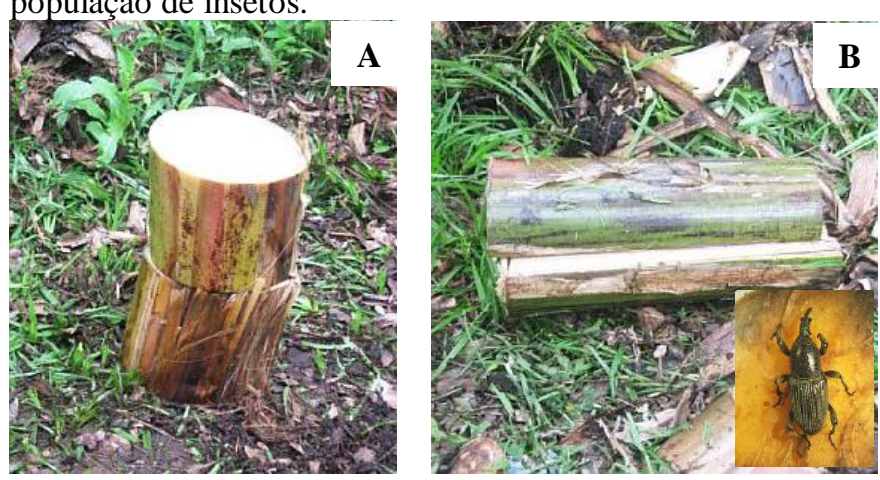

Fonte: EPAGRI (2015).

Com o resultado do monitoramento, observou-se que a população da broca era elevada e que a isca tipo telha 
apresentou melhor resultado, capturando uma maior quantidade de insetos.

Para a aplicação, os fungos entomopatogênicos $B$. bassiana e $M$. anisopliae foram preparados com água destilada nas proporções de 0,0 (controle) $5,10,15$ e $20 \mathrm{~g} \mathrm{~L}^{-1}$. Em seguida, esta solução foi pincelada dos dois lados da isca, sendo, então cobertas e colocadas duas finas tiras de folhas entre as duas partes para facilitar a exalação do cheiro e a entrada dos adultos.

A aplicação foi realizada em iscas tipo telha, de $50 \mathrm{~cm}$ de comprimento. As iscas foram feitas de pseudocaules de bananeiras recém-colhidas, dando-se preferência em fazer apenas duas iscas de cada pseudocaule, com o intuito de se manter a uniformidade e maior vida útil das iscas.

As avaliações foram semanais capturando-se e contando-se o número de insetos por armadilha. Após a segunda contagem, uma nova reposição das iscas era feita em função da deterioração das mesmas e o processo de aplicação dos fungos repetido. Seguiram-se a isto mais duas avaliações. Portanto, o trabalho durou 35 dias, contando-se desde o monitoramento populacional.

$\mathrm{O}$ delineamento estatístico usado neste ensaio foi $\mathrm{o}$ Delineamento Inteiramente Casualizado (DIC), em esquema fatorial $2 \times 5$, sendo dois tipos de fungos entomopatogênicos
(B. bassiana e $M$. anisopliae) e cinco concentrações $(0,0$ controle; 5,$0 ; 10 ; 15$ e $20 \mathrm{~g}$ ), com cinco repetições. Cada repetição foi composta por uma isca tipo telha de $50 \mathrm{~cm}$, representando assim uma unidade experimental. Os dados foram analisados com estatística realizada no programa estatístico ASSISTAT (SILVA; AZEVEDO, 2016), versão 7.6 beta $^{\circledR}$. Quando os tratamentos apresentaram significância, submeteu-se a comparação das médias ao teste de Tukey ao nível de significância de 1,0\% de probabilidade,

\section{RESULTADOS E DISCUSSÃO}

Na Figura 2, observa-se o monitoramento populacional de adultos e a quantidade de insetos da broca do rizoma $(C$. sordidus) capturados, em função do tipo de armadilha utilizada. Verifica-se que a isca tipo telha é mais eficiente na captura destes insetos.

Isso se deve possivelmente a maior área disponível para os insetos, em que o corte exala uma maior quantidade de atrativos. A isca tipo telha apresentava área de $1.250 \mathrm{~cm}^{2}$ enquanto a isca tipo queijo apenas $707 \mathrm{~cm}^{2}$. Assim, os insetos tem mais alimento, disponível com mais facilidade e também uma área maior para os mesmos se abrigarem.

Figura 2. Número de adultos de Cosmopolites sordidus capturados em função do tipo de isca utilizada. Utilizaram-se 20 armadinhas, 10 de cada tipo.

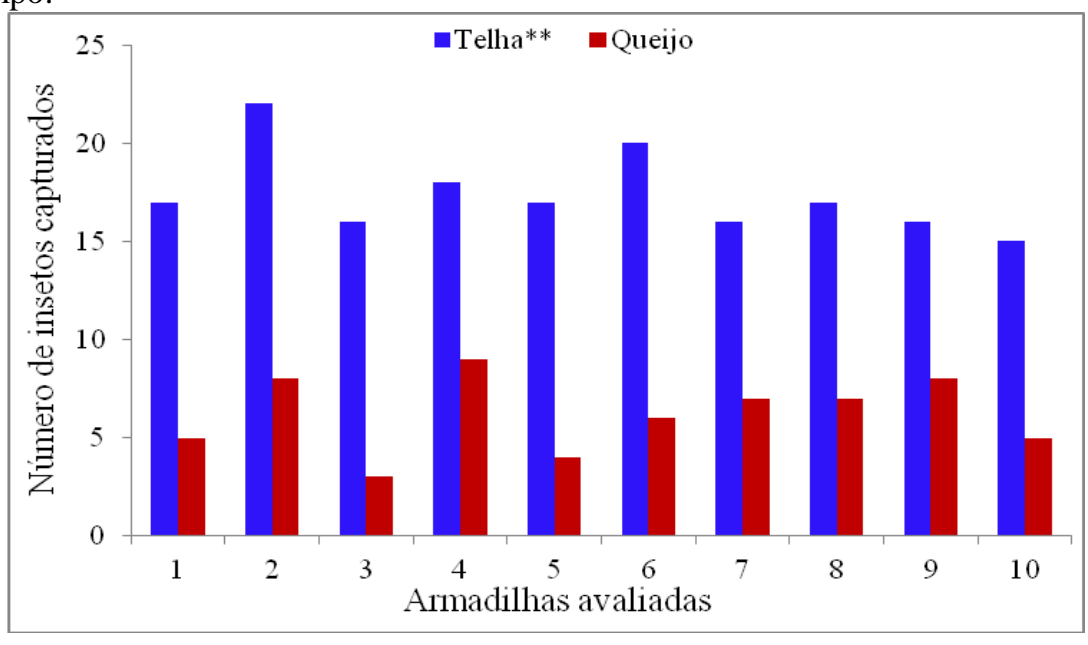

Segundo Rossetti (2013) é fundamental que antes de realizar qualquer tipo de controle da broca do rizoma proceda-se de uma amostragem para se conhecer a população e constatar o potencial risco da mesma. As amostragens periódicas são necessárias para saber há necessidade ou não de controlar a praga e quando ela atinge níveis de controle.

Verifica-se, que houve diferença significativa entre os dois fungos utilizados neste ensaio, com nível de 1,0\% $(\mathrm{p} \leq 0,0042)$. Observa-se também que as concentrações a que foram submetidas os insetos proporcionou diferença significativa, ao nível de $5 \%(\mathrm{p} \leq 0,0221)$. A interação entre fungos $\mathrm{e}$ as concentrações não apresentou diferença significativa.

Michereff Filho et al., (2010) avaliando metodologias para inoculação de $B$. bassiana, verificaram que o deslocamento dos insetos numa superfície contamina é suficiente para que o mesmo seja contaminado e também infectado. Acrescenta-se a isso que, desta forma simula a contaminação que acontece no bananeiral, com o deslocamento natural dos insetos em campo.

Este resultado evidencia a importância desta espécie, como formidável agente do controle biológico de insetos, visto que este fungo pode afetar mais de 200 espécies. Além disso, trata-se do agente de controle biológico mais eficiente, utilizado em todo mundo, sendo empregado em escala comercial em alguns países, como Estados Unidos, México, Argentina e Brasil.

Na Figura 3 A e B, observa-se as médias de insetos adultos capturados, em função do tipo de fungo e da quantidade que os mesmos foram aplicados, respectivamente. Observa-se que o fungo B. bassiana, mostrou-se mais efetivo na redução populacional da broca do rizoma. Pois houve uma maior quantidade de insetos capturados. Ressalta-se, ainda Figura 3B, que a partir da quantidade de 10,15 e $20 \mathrm{~g}$ do produto comercial a base de B. bassiana foi a que obtevou-se melhores resultados, sendo capturados, 15,8, 17,7 e oito insetos, respectivamente. Para o produto a base de $M$. 
anisopliae, verifica-se que não houve resultado satisfatório na redução de captura de insetos.

Para o fungo $M$. anisopliae não se verificou redução na quantidade de insetos com o aumento das concentrações. Um dos aspectos que pode ser sugerido, é que o efeito provocado por $B$. bassina sobre $C$. sordidus seja agudo, enquanto para M. anisopliae, possa ser mais lento, em função do maior tempo que este fungo necessite para infectar de forma irreversível os insetos infectados, ocasionando assim um efeito retardado.
Estes resultados são discordantes dos encontrados por Almeida (2005) que observaram redução de superir a 60\%, contudo in vitro para o controle de Antonomus grandis com M. anisopliae var. anisopliae. Vale salientar que Alves (1998) informa que as condições ambientais exercem grande influência sobre os entomopatógenos e sendo essas adversas, o controle microbiano torna-se prejudicado, justificando-se as pesquisas com a finalidade de se selecionar, induzir e melhorar linhagens que apresentam características úteis para o êxito de seu emprego no campo.

Figura 3. Número médio de insetos capturados em função do fungo utilizado (A); média do número de insetos capturados em função das concentrações dos fungos (B. bassiana e M. anisopliae) utilizados no controle biológico de $C$. sordidus.

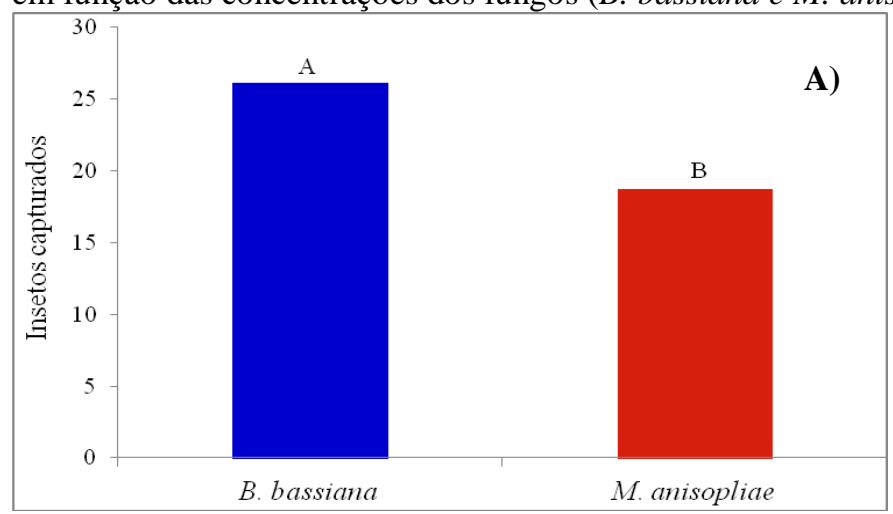

Na Figura 4, verifica-se a disposição dos tratamentos no campo, onde verifica-se que independente de isca está mais na periferia ou num local central de cultivo, a quantidade de insetos capturados por isca não seguiu nenhuma tendência.

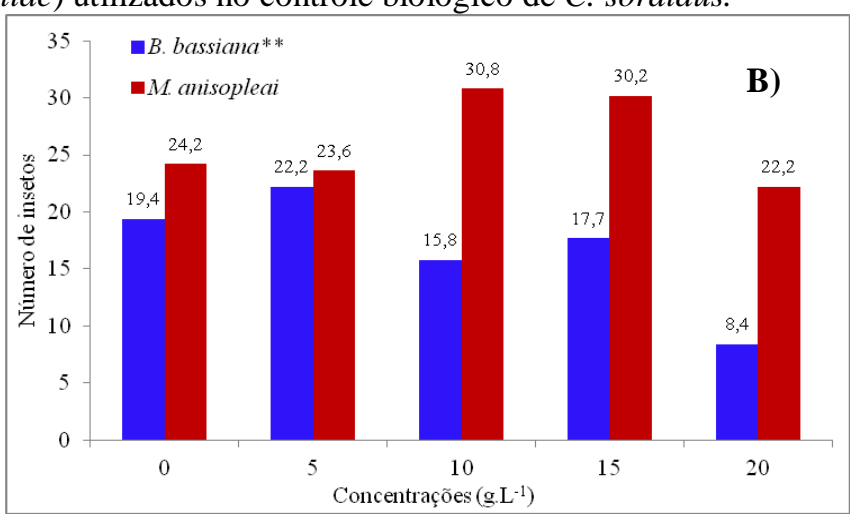

Confirmando assim, que a área de plantio comercial estava infestada de forma homogênea, conforme se observou no monitoramente pré ensaio. Ressalta que em $72 \%$ das iscas observou-se mais de 15 insetos adultos.

Figura 4. Disposição dos tratamentos no campo, mostrando a quantidade de insetos capturados por isca, ao longo do tempo do ensaio.

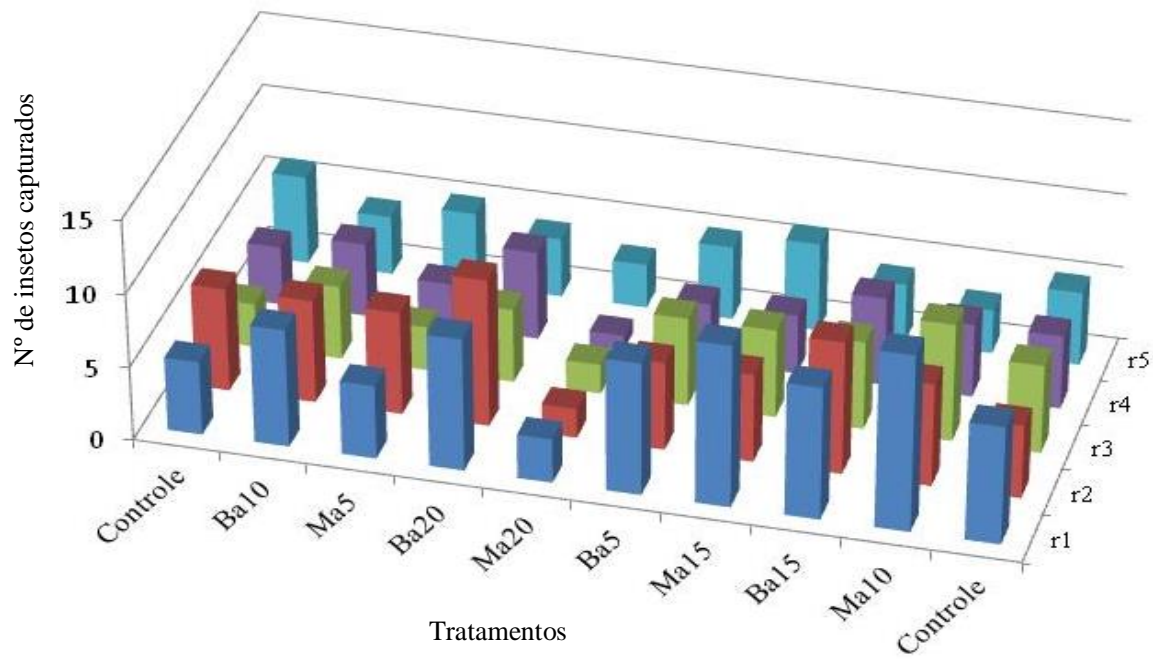

Na Figura 5, verifica-se à quantidade de insetos adultos capturados em função do avanço nas avaliações realizadas. Observa-se que à medida que avança o número de avaliações diminui a quantidade de insetos capturados para os dois fungos estudados, sendo, contudo, mais efetivo para $B$. bassiana. Enquanto, na primeira avaliação observaram-se capturas de até 19 insetos por isca, na quarta avaliação este valor não passou de oito insetos adultos capturados, uma redução de aproximadamente $58 \%$.

Isso se deve provavelmente ao efeito massal da captura e morte dos insetos adultos na área e também do efeito dos fungos sobre outros insetos adultos e também de fases larvais, pela contaminação das galerias dos rizomas. A eficácia do parasitismo do fungo $B$. bassiana nas concentrações de 10,15 e 20 gramas, proporcionou uma eficiência muito satisfatória, quando comparada com o controle, tendo em vista que houve uma porcentagem de controle superior a $75 \%$. Salienta-se que houve redução também nas iscas controle, isso ocorreu provavelmente, porque, depois do inseto ter sido contaminado pelo fungo ele dispersou para a área onde estavam as isca controle. 
Figura 5. Quantidade de insetos capturados em função das avaliações para os fungos B. bassiana e M. anisopliae nas concentrações testadas para o controle de C. sordidus.

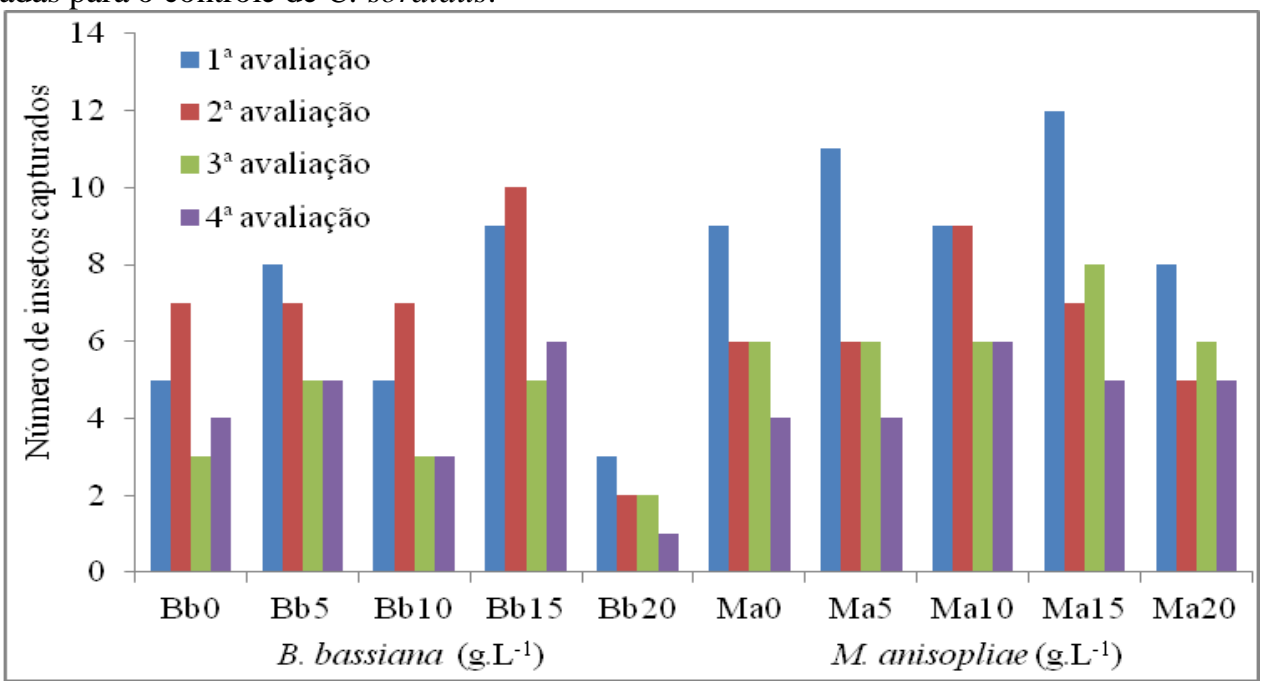

Sugere-se que diminuição possa ser ação entomopatogênica dos fungos, pois com cerca de 20 dias após a primeira aplicação, foi possível observar contaminação da área com os fungos, pois observou-se após este lapso de tempo a presença de alguns insetos adultos mortos e recobertos com hinfas. Este sistema pode ser chamado de autodisseminação, pois são os próprios insetos contaminados que levam para as galerias o fungo aderido ao seu corpo, sendo os mesmos removidos ao longo do tempo pelo atrito do corpo dos insetos com outras superfícies ao longo do deslocamento.

Assim que os conídios entram na hemolinfa do inseto o fungo se multiplica e logo há uma massa hifal considerável. O inseto morre e, assim, com o esgotamento dos nutrientes, e havendo condições favoráveis, o fungo emerge, exteriorizando suas hifas e forma uma massa branca na superfície do cadáver (Lazzarini, 2005). Então essa massa hinfal, advinda dos cadáveres/carcaças, atua naturalmente como inoculante na área que foi anteriormente tratada, mantendo destarte, um nível de fungos na área elevado, contribuindo assim, para uma maior possibilidade de contaminação dos insetos e, consequentemente, redução do nível populacional dos insetos na área.

Segundo Santoro et al., (2007) a germinação dos conídios e a consequente produção de enzimas para degradar a cutícula iniciam-se após sua adesão ao hospedeiro, sendo assim, acredita-se que o menor número de insetos observados nas últimas avaliações pode ser atribuída a morte dos que entraram em contato com as maiores quantidades (concentrações) de fungos aderidos ao corpo dos insetos.

A menor quantidade de insetos observada também nas testemunhas, ao longo das avaliações, deve-se provavelmente, ao fato da redução populacional da área, como um todo.

Akello et al., (2007) constataram que o fungo $B$. bassiana permanece ativo no campo, seja em rizoma, raízes ou pseudocaule por um período de até 4 meses após a inoculação. Estes mesmos autores sugerem que uma forma de se prevenir a entrada/contaminação da área com $C$. sordidus seria a aplicação de uma solução contendo $B$. bassiana nas plantas ainda nos viveiros, ou antes, do plantio direto no campo, como uma forma de estimular o desenvolvimento do fungo e o mesmo já começar a atuar na presença dos primeiros insetos a entrarem na área. Portanto, seria uma medida preventiva, o que infelizmente, não é uma atitude comum em nossos produtores e técnicos.

A aquisição deste produto no Brasil, não é fator limitante, visto que são produzidos muitos inseticidas a base do fungo entomopatogênico B. bassiana, os quais podem ser utilizados em programas de controle biológico de pragas em diferentes culturas (DALZOTO; UHRY, 2009).

Gravena (2007) salienta que ao empregar fungos entomopatogênicos no controle biológico de pragas é importante ter bastante cuidado com os agrotóxicos (inseticidas, herbicidas), e, até mesmo produtos naturais, como os derivados de nim (Azadirachta indica) que é considerado um produto natural de largo espectro, pois estes podem acarretar efeitos sobre os microrganismos, afetando seu desempenho em campo. Assim é aconselhável buscar informações sobre a compatibilidade destes produtos com os agrotóxicos.

É sabido que já existem defensivos químicos compatíveis com fungos entomopatogênicos que, quando testados em condições de laboratório, demonstraram que a combinação de fungos e defensivos químicos pode ser uma alternativa para pragas de difícil controle, cometam (CAVALCANTI et al., 2002).

Gallo et al., (2002) enumera algumas limitações do controle biológico, dentre elas está o tempo de resposta deste tipo de controle, já que o problema é inadiável, e que estes agentes microbianos tem que se adaptarem, reproduzirem e se manterem num nível elevado, em campo; é especifico, e, infelizmente, o número de pragas é cada vez maior; e outro fator de extrema limitação é a falta de conhecimento por parte dos técnicos, pois trata-se de um manejo contínuo, seguindo algumas normas que são fundamentais a para o sucesso do empreendimento.

O controle da broca da bananeira é essencial nos cultivos comerciais, pois as galerias produzidas por suas larvas também podem funcionar como porta de entrada de fitopatógenos, como o fungo (Fusarium oxysporum f. sp. cubense), que é o causador do mal-do-panamá. Além disso, as larvas depositam fezes de consistência lamacenta, dificultando o controle por causa do impedimento da penetração de inseticidas líquidos e gasosos no interior do rizoma (GOMES, 2006). 
Avaliando por outros aspectos, segundo Almeida e Machado (2006) os fungos entomopatogênicos são patógenos bastante usados no controle de insetos, já que são capazes de atacar um grande número deles em praticamente todos os estágios de desenvolvimento. Além disso, possuem elevada variabilidade genética, permitindo estudos de seleção de distintas cepas e avaliação das mais virulentas para o controle de pragas. Agregado a isso, os fungos entomopatogênicos podem afetar as gerações seguintes, diminuindo a oviposição, a viabilidade de ovos e aumentando a sensibilidade da população a outros agentes biológicos e químicos.

Fator imprescindível que se deve levar em conta no controle dos fitopatógenos é a rapidez com eles agem. Essa rapidez com que o patógeno mata seu hospedeiro é uma característica desejável para o controle de muitas pragas agrícolas, contudo, não deve ser considerada como única. É imperativo também, que o isolado seja capaz de proporcionar elevada mortalidade final, exigindo, desta maneira, pulverizações menos frequentes, e, possibilitando-se reduzir os custos de controle das pragas de acordo com Tamai et al., (2002) apud Costa et al., (2010), conforme se verificou também neste ensaio.

Os resultados observados são muito animadores, no sentido de se utilizar de forma mais intensiva sistematizada o controle biológico em larga escala. De acordo com Mesquita (1999) apud Moura et al. (2015) o controle biológico aparece como uma alternativa tecnológica de baixo impacto com potencial para contribuir no restabelecimento do equilíbrio biológico da broca do rizoma no meio ambiente aumentando a produtividade, a renda e, consequentemente, a melhoria na qualidade de vida dos pequenos produtores.

Portanto, faz-se o fechamento destes resultados com as palavras de Moura et al. (2015) que nos afirma ser o controle biológico é uma alternativa viável com efeito positivo pois, além de reduzir os riscos de intoxicação do homem e dos animais, evita a poluição e o desequilíbrio do meio ambiente, não é tóxico e, com certeza, muito mais econômica.

\section{CONCLUSÕES}

O controle biológico de Cosmopolites sordidus com fungos entomopatogênicos é viável, contudo, necessita de conscientização do produtor para iniciar sua aplicação antes da praga se instalar na cultura;

O fungo Beauveria bassiana foi mais efetivo que Metharizium anisopliae no controle de C. sordidus;

A dosagem mais efetiva no controle de $C$. sordidus foi de 20,0 g de B. bassiana;

Com o avanço das épocas de avaliação há diminuição na quantidade de insetos adultos capturados.

\section{AGRADECIMENTOS}

A empresa Itaforte Bio Produtos Agro-Florestais ${ }^{\circledR}$ Ltda, que nos cedeu os produtos comerciais BOVERIL $W P^{\circledR} \mathrm{e}$ METARRIL $W P^{\circledR}$, a base de dois fungos entomopatogênicos (B. bassiana e M. anisopliae) para esta pesquisa e ao produtor Sr. Manuel Teixeira que nos cedeu a sua área de produção comercial para realizarmos este trabalho; e ao IFCE Campus Sobral, por disponibilizar a logística para a realização desta pesquisa.

\section{REFERÊNCIAS}

AKELlO, J.; DUBOIS, T.; COYNE, D.; GOLD, C. S.; KYAMANYWA, S. Colonization and persistence of the entomopathogenic fungus, Beauveria bassiana, in tissue culture of banana. African Crop Science Conference Proceedings. v. 8; p. 857-861. 2007.

ALMEIDA, A. M. B.; BATISTA FILHO, A.; TAVARES, F. M.; LEITE, L. G. Seleção de isolados de Beauveria bassiana para o controle de Cosmopolites sordidus (Germar, 1824) (Coleoptera: Curculionidae). Arquivos Instituto Biológico., São Paulo, v.76, n.3, p.489-493, jul./set., 2009.

ALMEIDA, J. C. Patogenicidade e viabilidade de Beauveria bassiana, Metarhizium anisopliae var. anisopliae e Metarhizium anisopliae var. acridum ao Anthonomus grandis (Boheman) (Coleoptera: Curculionidea). 154f. (Tese de Doutorado em Ciências Biológicas). Universidade Federal de Pernambuco-UFPE. Recife-PE. 2005.

ALMEIDA, J. E. M.; MACHADO, L. A. Fungos entomopatogênicos. Boletim Técnico: Controle Biológico de Insetos e Ácaros, Instituto Biológico, São Paulo, n. 15, p. 1327, 2006.

ALVES, S. B. Fungos entomopatogênicos. In: Alves, S. B. (Org.). Controle Microbiano de Insetos. Piracicaba: FEALQUSP, p. 289-371. 1998.

BATISTA FILHO, A. TAKADA, H. M.; RAGA, A.; SATO, M. E.; CARVALHO, A. G. Controle Biológico da Broca da Bananeira. In: REUNIÃO ITINERANTE DE FITOSSANIDADE DO INSTITUTO BIOLÓGICO, 8., 2005, Registro. Anais... Registro: IB/APTA/UNESP, 2005.

BORGES, A. L.; SILVA, T. O.; CALDAS, R. C.; ALMEIDA, I. E. Adubação nitrogenada para bananeira'terra'(Musa sp. AAB, subgrupo Terra). Revista Brasileira de Fruticultura, Jaboticabal, v. 24, n. 1, p. 189-193, 2002.

CAVALCANTI, R. S.; MOINO JUNIOR, A.; SOUZA, G. C.; ARNOSTI, A. Efeito dos produtos fitossanitários fenpropatrina, imidaclopride, iprodione e tiametoxam sobre o desenvolvimento do fungo Beauveria bassiana (Bals.) Vuill. Arquivos do Instituto Biológico, São Paulo, v. 69, n. 3, p. $17-$ 22, 2002.

CONTROLE BIOLÓGICO. Disponível em: http://www.megabio.com.br/controlebiologico.html. Acesso em: 10 out. 2016.

COSTA, J. N. M.; SILVA, C. A.; TEIXEIRA, C. A. D.; SALLET, L. A. P.; ROCHA, R. B.; TELES, B. R. Isolados de Beauveria bassiana para o controle biológico da brocadorizoma-da-bananeira (Cosmopolites sordidus, Germar) (Coleoptera: Curculionidae). Porto Velho, RO: Embrapa Rondônia, 2010. 13p. - (Boletim de Pesquisa e Desenvolvimento / Embrapa Rondônia, 1677-8618; 68).

DALZOTO, P. R.; UHRY, K. F. Controle biológico de pragas no Brasil por meio de Beauveria bassiana (Bals.) Vuill. 
Biológico, (divulgação técnica). São Paulo, v.71, n.1, p. 3741, 2009.

EMBRAPA. Centro Nacional de Pesquisa de Solos. Sistema Brasileiro de Classificação de Solos. Brasília, 412p. 1999. (EMBRAPA/CNPS-RJ. Documentos, 5).

EPAGRI. Informações Técnicas. Banana. Disponível em: < http://www.epagri.sc.gov.br/?page_id=1349\#>. Acesso: 17 out. 2017.

GALLO, D.; NAKANO, O.; WIENDL, F. M.; SILVEIRA NETO, S.; CARVALHO, R. P. L. Entomologia Agrícola. Piracicaba, ed. Agronômica Ceres. 920p. 2002.

GOMES, R. P. Fruticultura brasileira. 13. ed. São Paulo: Nobel, 446p. 2006.

GRAVENA, S. Manejo ecológico da broca-do-café com inseticidas biológicos. In: DIA DO MANEJO DE PRAGAS DO CAFÉ. 1., 2006. Palestras. Disponível em: <http://www.itafortebioprodutos.com.br/news.asp?id_NWS= 11>. Acesso: 12 de set. 2016.

IBGE. Levantamento sistemático da produção agrícola. 2012. Disponível em: <http://www.sidra. ibge.gov. br/bda/prevsaf/default.asp>. Acesso em: 27 out. 2016.

LAZZARINI, G. M. J. Efeito da umidade sobre a germinação in vitro de Beauveria bassiana e Metarhizium anisopliae e atividade contra Triatoma infestans. 46f. Dissertação (Mestrado em Parasitologia) - Instituto de Patologia Tropical e Saúde Pública, Universidade Federal de Goiás, Goiânia, 2005.

LEITE, L. G.; ALVES, S. B.; TAKADA, H. M.; BATISTA FILHO, A.; ROBERTS, D. W. Occurrence of Entomophthorales on spittlebugs pests of pasture in eastern São Paulo state, Brazil. Arquivos Instituto Biológico, São Paulo, v. 69, n. 3, p. 63-68, 2002.

LINS, L. C. R.; FANCELLI, M.; RITZINGER, C. H. S. P.; COELHO FILHO, M. A.; LEDO, C. A. S. Torta de mamona no controle da broca-do-rizoma (Cosmopolites sordidus) em bananeira-terra. Revista Brasileira de Fruticultura., Jaboticabal - SP, v. 35, n. 2, p. 493-499, Junho, 2013.

MICHEREFF FILHO, M.; FANCELLI, M.; NEVES, P. M. O. J.; TIGANO, M. S.; LOPES, R. B.; OLIVEIRA, S. O. D.; OLIVEIRA, M. W. M. Metodologia de inoculação de Beauveria bassiana para avaliação da virulência em adultos de Cosmopolites sordidus (Coleoptera: Curculionidea). (Boletim de Pesquisa e Desenvolvimento, 47). 24p. 2010.

MOURA, N. A.; SILVA, A. F.; BORGES, V. E.; VILLAR, M. L. P. Avaliação do controle biológico da broca de rizoma da bananeira (Cosmopolites sordidus Germ., 1824) utilizando o fungo entomopatogênico Beauveria bassiana (Bals.) Vuill. REB. v. 8 (2): 249-266, 2015.

ROSSETTI, N. C. S. Controle biológico e comportamental do moleque-da-bananeira. Disponível em: <http://www.esalq.usp.br/cprural/boapratica/mostra/85/contro le-biologico-e-comportamental-do-moleque-dabananeira.html>. Acesso: 15 set. 2016.

SANTORO, P. H.; NEVES, P. M. O. J.; ALEXANDRE, T M.; ALVES, L. F. A. Interferência da metodologia nos resultados de bioensaios de seleção de fungos entomopatogênicos para o controle de insetos. Pesquisa Agropecuária Brasileira. Brasília. v. 42, p. 483-489. 2007.

SILVA, F. A. S.; AZEVEDO, C. A. V. The Assistat Software Version 7.7 and its use in the analysis of experimental data. Afr. J. Agric. Res, v.11, n.39, p.3733-3740, 2016.

SILVA, V. F.; MOREIRA, F. J. C.; LUNA, N. S.; ARAÚJO, O. P.; SEABRA FILHO, M. Controle de Cosmopolites sordidus com os fungos entomopatogênicos Beauveria bassiana e Metarhizium anisopliae em banana. In: Congresso de Pesquisa e Inovação, da Rede Norte Nordeste de Educação Tecnológica - CONNEPI, 7, 2011, Natal, Anais... Natal: SETEC/MEC, p.444-453, 2011.

TIAGO, P. V.; SILVA, R. J. DA. Atividade proteolítica de isolados de Metarhizium anisopliae sobre substratos cuticulares e não-cuticulares. Ciência Rural. v. 37, n. 1, p. 26-30. 2007. 